Article

\title{
Smart-Autonomous Wireless Volatile Organic Compounds Sensor Node for Indoor Air Quality Monitoring Application
}

\author{
C. Bambang Dwi Kuncoro ${ }^{1, * \mathbb{D}}$, Moch Bilal Zaenal Asyikin ${ }^{1} \mathbb{(}$ and Aurelia Amaris ${ }^{2}$ \\ 1 Department of Refrigeration, Air Conditioning and Energy Engineering, National Chin-Yi University \\ of Technology, Taichung 41170, Taiwan; bilalmoch@gmail.com \\ 2 Department of Informatics Engineering, Faculty of Computer Science, Universitas Brawijaya, \\ Malang 65145, Indonesia; aureliamariss@gmail.com \\ * Correspondence: bkuncoro@ncut.edu.tw; Tel.: +886-4-239-24505 (ext. 8274)
}

check for

updates

Citation: Kuncoro, C.B.D.; Asyikin,

M.B.Z.; Amaris, A. Smart-

Autonomous Wireless Volatile Organic Compounds Sensor Node for Indoor Air Quality Monitoring Application. Int. J. Environ. Res. Public Health 2022, 19, 2439. https:// doi.org/10.3390/ijerph19042439

Academic Editors: Tom Cole-Hunter, Mark J. Nieuwenhuijsen and Pau B. Tchounwou

Received: 30 December 2021 Accepted: 18 February 2022 Published: 20 February 2022

Publisher's Note: MDPI stays neutral with regard to jurisdictional claims in published maps and institutional affiliations.

Copyright: (C) 2022 by the authors. Licensee MDPI, Basel, Switzerland. This article is an open access article distributed under the terms and conditions of the Creative Commons Attribution (CC BY) license (https:// creativecommons.org/licenses/by/ $4.0 /)$.

\begin{abstract}
Several studies reported the significant effect of indoor air quality on human health, safety, productivity, and comfort because most humans usually conduct $80 \%-90 \%$ of their activity inside the building. This is generally due to the fact that indoor pollution is associated with volatile organic compounds (VOCs), pollutants with chronic health effects, both non-carcinogenic and carcinogenic, on humans. Therefore, this study focused on developing wireless VOCs sensor nodes with a lowpower strategy feature to perform an autonomous operation in indoor air quality monitoring (IAQM). The sensor node mainboard consists of a microcontroller-based AVR (ATmega-4808) that supports a low power mode and low-power IAQ-Core sensor for VOCs detection. The low-power sensing algorithm developed also allowed the sensor node to consume a total power of $0.22 \mathrm{mAh}$ for one cycle of operation, which includes the initial process, TVOCs value reading process, data transmitting process, and low power mode process at a time interval of $30 \mathrm{~min}$. The most significant power was observed to be consumed in the data transmitting process with $0.13 \mathrm{mAh}$ or $58 \%$ of total power consumption in one cycle of sensor node operation. Furthermore, the 10F capacitance of the supercapacitor was able to drive the VOCs sensor node for $139 \mathrm{~s}$ and it was recommended that further studies use micro energy harvesting (from an indoor environment) to extend its lifetime. The 1541-minute field experiment conducted also showed that TVOCs and $\mathrm{CO}_{2}$ values were successfully measured and displayed over an internet connection on the monitoring terminal dashboard. The recorded real-time TVOCs value of $175 \mathrm{ppb}(<200 \mathrm{ppb})$ indicates good air quality.
\end{abstract}

Keywords: IAQM; TVOCs; sensor node; low power

\section{Introduction}

The 2030 Agenda for Sustainable Development pays serious attention to healthy living. This is indicated in Goal 3 (3.9), which is targeted towards reducing the number of deaths caused by pollution and contamination, as well as Goal 11 (11.1-11.3), which focuses on safety and health by gender, age, and persons with disabilities from different types of residence. Another goal (11.6-11.B) also targets air quality and solid waste in urban environments, public spaces, and cities with social and economic impacts [1]. Moreover, the development of science and technology promotes innovation in realizing healthy living with a focus on air pollution. This is considered necessary because the exploitation of natural resources, manufacturing activities, and the massive use of transportation are known to be producing unavoidable air pollution, which is very hazardous to human health and even has the ability to cause death [2,3]. Meanwhile, previous studies have shown that humans conduct $80 \%-90 \%$ of their activities indoors [3-6].

Indoor air pollution is usually caused by pollutants such as particulate matter (PM), volatile organic compounds (VOCs), chemical factors, and others existing in the air inside buildings. The most common form is VOCs, which are produced from hydrocarbons in 
materials normally used in the living environment such as aromatic compounds, liquid fuels, and paraffin [7]. VOCs are easily vaporized in the air when the vapor pressure is high and are unknowingly present in the environment all the time. It is important to note that the massive use of chemical substances needs to be monitored and avoided due to the harmful effects of the VOCs particles on human health such as throat irritation, headaches, coordination loss, fatigue, and several others [8,9]. Moreover, the concentration of VOCs indoors is higher than outdoors because those emitted inside are associated with fragrances and other consumer products [10]. This indicates there is a need to monitor these pollutants in order to increase health awareness.

Organizations such as the WHO [11], US EPA [12], and German Federal Environmental Agency [13] have issued some indoor air quality (IAQ) standards [14] to ensure continuous monitoring of indoor air pollution from all directions. Several studies focused on the optimal use of the sensor [15] in monitoring indoor air quality, while others compared its processor usage [16] and algorithm development [17,18]. In Ref. [19], particles such as carbon dioxide $\left(\mathrm{CO}_{2}\right)$, temperature, humidity, $\mathrm{PM}_{2.5}$, and VOCs were considered in IAQ monitoring with their variations observed to have been monitored successfully through the system developed, which was designed for flexible implementation and to support low-cost sensors. Another study [20] also monitored $\mathrm{CO}_{2}, \mathrm{NO}_{2}, \mathrm{HCHO}$, and TVOCs successfully using an ARM microcontroller-based LPC2478 equipped with automatic control of the heat exchange ventilator. The "poor" status in the monitoring system was designed to automatically trigger the heat-exchange ventilation operation and this was reported to have a better performance compared to another ventilation method, specifically the traditional natural method. Moreover, the authors of Ref. [21] developed a wireless gas sensor network for pollutant detection and explained the evolution of the prototype up to the fourth version, which is equipped with a solar panel. The sensor nodes were also powered by a Li-ion battery with a solar panel for outdoor application. The review conducted by [22] on the study of air quality monitoring between 2015 and 2020 discovered that Arduino, Raspberry, and ESP8266 modules were usually used as the main processing units. Several studies also considered using Bluetooth and the ZigBee platform instead of Wi-Fi as the communication protocol due to their power efficiency.

It was observed that most of these previous studies focus on the sensor to detect pollutants and measure air quality parameters. Meanwhile, a power strategy needs to be a concern for continuous, real-time, and stand-alone sensor node operation in air quality monitoring systems. This is essential for long-term operation or sensor node lifetime durability considering the fact that a built-in battery is normally used as its main power source. According to [23], the detection of atmospheric carbon dioxide and methane requires low power consumption with a highly sensitive sensor, and the application of the device in a different place for around nine months showed that it has a good result. It is important to note that the stand-alone status of a sensor node in an indoor air quality monitoring system sometimes makes it non-optimal to replace and substitute the battery when it runs because it is not effective, costly, and raises some environmental issues.

This present study was conducted to develop an air quality sensor node with a compact size and a new powering technique for autonomous operation in an indoor air quality monitoring (IAQM) system. The node was built based on a modular approach with the focus on the measure of the VOCs parameters in real time, after which the data are to be sent to the cloud through a transmit algorithm implemented in order to ensure low power consumption. Moreover, a dashboard placed in the monitoring terminal was designed to monitor and trace the VOCs concentration to determine the indoor air quality levels as excellent, good, moderate, poor, or unhealthy. This low-power strategy developed can be utilized in further studies in creating a VOCs sensor node system to receive input power from micro energy harvesting in the indoor environment. 


\section{Materials and Methods}

\subsection{Volatile Organic Compounds (VOCs)}

VOCs are a wide group of organic chemical compounds found in several products that vaporize easily into the environment under normal conditions. They have high volatility, mobility, and resistance to degradation, thereby allowing their movement through vast distances [24]. Their concentration in the space is usually a balance between the net emissions in the area and the supplies from the ventilation such that the existence of a high concentration of TVOCs in a building possibly indicates the presence of a strong pollutant or inadequate general or local ventilation [25]. This means it is possible to determine the insufficient or poor ventilation design in a building using this factor and a higher value indicates a higher concentration level as shown in Table 1. It is important to reiterate that TVOCs usually affect the sense of well-being and comfortability inside a building. Some of their particles include methylene chloride, tetrachloroethylene, toluene, benzene, ethylene glycol, and formaldehyde.

Table 1. TVOCs' level of concentration [9].

\begin{tabular}{cccc}
\hline TVOCs Level $\boldsymbol{\mu g} / \mathbf{m}^{\mathbf{3}}$ & TVOCs Level (ppb) & $\begin{array}{c}\text { Level of } \\
\text { Concentration }\end{array}$ & Air Quality \\
\hline$<300$ & $<67$ & Level 1 & Excellent \\
$300-1000$ & $67-222$ & Level 2 & Good \\
$1000-3000$ & $222-665$ & Level 3 & Moderate \\
$3000-10,000$ & $665-2218$ & Level 4 & Poor \\
$10,000-25,000$ & $2218-5545$ & Level 5 & Unhealthy \\
\hline
\end{tabular}

TVOCs are measured in milligram per cubic meter $\left(\mathrm{mg} / \mathrm{m}^{3}\right)$ or part per billion (ppb). The conversion from $\mathrm{mg} / \mathrm{m}^{3}$ to $\mu \mathrm{g} / \mathrm{m}^{3}$ or part per million ( $\mathrm{ppm}$ ) is expressed in Equation (1) [26].

$$
\rho_{\text {gas mix }}\left[\mu \mathrm{g} / \mathrm{m}^{3}\right]=\frac{M_{\text {gas mix }}[\mathrm{g} / \mathrm{mol}]}{V_{m} \times 1000 \mathrm{ppb}} \times c_{\text {gas mix }}[\mathrm{ppb}]
$$

where $\rho_{\text {gas mix }}, M_{g a s \text { mix }}$, and $c_{\text {gas mix }}$ are the mass concentration, the average molar mass, and the particle concentration of the defined gas mix, respectively, while $V_{m}$ is the molar volume, which is $0.0244 \mathrm{~m}^{3} / \mathrm{mol}$ at $25^{\circ} \mathrm{C}$, and the atmospheric pressure and the mean molar mass of this mixture is $110 \mathrm{~g} / \mathrm{mol}$.

\subsection{Low-Power Strategy}

A real-time VOCs monitoring requires real-time data transmission from the acquisition devices. The system developed in this study is configured to read the indoor TVOCs parameters and transmit the data to the server to be displayed in the monitoring dashboard. Meanwhile, the changes in the indoor air quality are not rapid, and this condition can be used as an opportunity to reduce power consumption through the implementation of an appropriate time strategy. This is possible because setting up the time interval to transmit data is one of the methods to ensure a low-power system considering the fact that a data logging device generally requires more power when transmitting data [27]. Moreover, high data transmitting frequency is directly proportional to power consumption. Another strategy is to use a chip that supports sleep mode when the system is not transmitting data. Some AVR chips support three sleep modes including idle, standby, and power down, which are considered suitable for the low-power system with some interfaces and features on the processor disabled during this mode to reduce the power consumption in the system. 


\subsection{Energy Storage}

This study used the supercapacitor to store energy instead of a battery due to its high energy density and ability to supply the quick bursts of demanded power rapidly [28]. However, the charging process of the supercapacitor requires a regulator circuit to keep the voltage and current according to the specification considering the fact that a ripple current can reduce its lifetime [29]. The supercapacitor has been previously used in [30] to store power from a piezo electronics generator and was reported to have the ability to function in the low-power system at a power consumption unit of $67 \mu \mathrm{W}$. This is observed to be in line with the long-term goal of developing a VOCs sensor node system to receive input power from the energy-harvesting process in the indoor environment.

\subsection{Design Overview}

This study developed a smart, autonomous, wireless sensor node to be applied in monitoring indoor air quality. The proposed device comprises four major units including the energy storage, sensor, processor, and wireless transceiver as shown in the functional block diagram presented in Figure 1. The entire units of the proposed device are designed to be powered by rechargeable energy storage in line with the plan for future autonomous devices coupled with an energy harvesting system. The processor used is a microcontrollerbased AVR and supports low power mode. Moreover, the system is equipped with a Wi-Fi module that connects it to the internet for data transmission purposes. The power source is a supercapacitor while the external power supply is designed to be used during the charging process and released during the discharging process for the supercapacitor to function. However, the system is expected to be linked to indoor energy harvesting as a power source in the future.

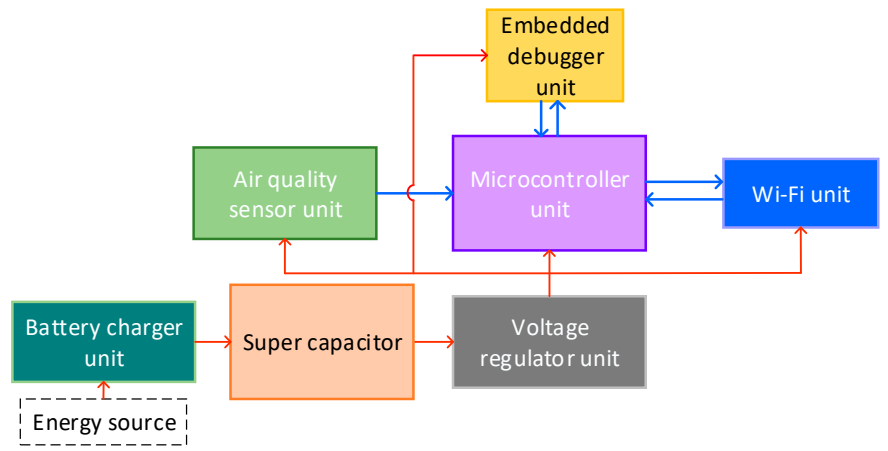

Figure 1. IAQ sensor node architecture.

\subsubsection{Mainboard}

The proposed device was designed to be compact, small, and work based on AVR ATmega-4808. All the system units including the power source component are integrated into the board as indicated in the 3D board design presented in Figure 2. It is also important to note that all the components used are SMD in order to achieve the low-power system design.

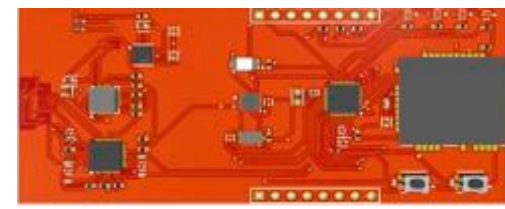

(a)

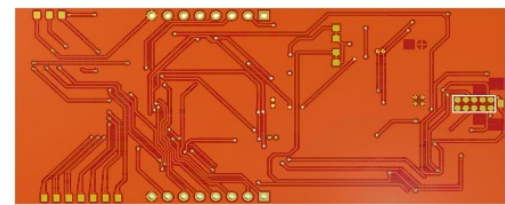

(b)

Figure 2. PCB design of IAQ sensor node: (a) top layer and (b) bottom layer.

The system was designed to read the VOCs sensor through the $\mathrm{I}_{2} \mathrm{C}$ interface and send data to the cloud through Wi-Fi communication. It was also designed to work in the 3.3-5 V 
voltage range, thereby making the supercapacitor a suitable power source. The overall specifications of the system are presented in Table 2.

Table 2. System specification.

\begin{tabular}{ccc}
\hline Parameters & Value & Remarks \\
\hline Power & $3.3-5.5 \mathrm{~V}$ & Supercapacitor \\
Interface & $\mathrm{I}_{2} \mathrm{C}, \mathrm{Wi}-\mathrm{Fi}$ & \\
Sensing range [31] & $450-2000 \mathrm{ppm}$ & $\mathrm{CO}_{2}$ equivalents \\
& $125-600 \mathrm{ppb}$ & TVOCs equivalents \\
\hline
\end{tabular}

\subsubsection{Supercapacitor}

Two parallel supercapacitors were used as the main power source with each having 5.0 F/5.5 V and the total capacity was calculated to be $10 \mathrm{~F}$ using Equation (2).

Capacitor in parallel connection:

$$
\mathrm{C}_{\mathrm{eq}}=\mathrm{C}_{0}+\mathrm{C}_{1}+\ldots+\mathrm{C}_{\mathrm{n}}
$$

The supercapacitor was tested by measuring its voltage during the charging and discharging process using Arduino Uno analog input. The charging process was conducted by connecting the system developed with an external power supply, and an Arduino Uno was programmed to monitor the supercapacitor voltage. The time required for this process from a voltage of 3.2-4.2 V was $85 \mathrm{~s}$. Meanwhile, the discharging process involved using the supercapacitor to power the VOCs sensor node and the time required to drive the minimum voltage for the system at 3.2V was $139 \mathrm{~s}$, as indicated in Figure 3. The supercapacitor charging capacity was found to be $2.7 \mathrm{mAh}$ using Equation (3) and the data tested.

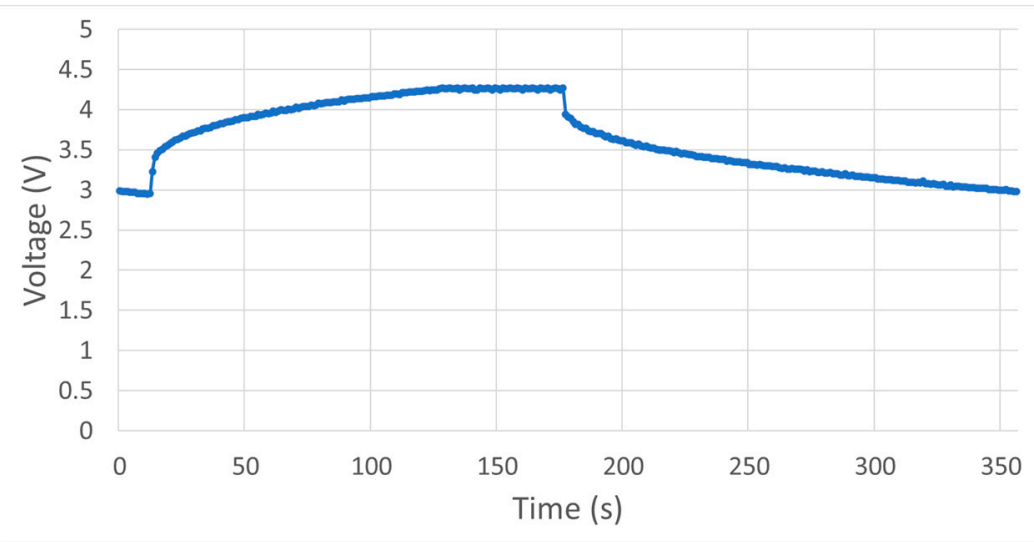

Figure 3. Supercapacitor test.

Supercapacitor charging capacity $\left(Q_{\mathrm{sp}}\right)$ [32]:

$$
\mathrm{Q}_{\mathrm{sp}}=\frac{\mathrm{C}\left(\mathrm{V}_{\mathrm{c}}-\mathrm{V}_{\mathrm{d}}\right)}{3600}
$$

where:

$\mathrm{Q}_{\text {sp }}=$ supercapacitor charging capacity in Amper.hour (Ah).

$\mathrm{C}=$ capacitance in Farad $(\mathrm{F}=\mathrm{A} . \mathrm{s} / \mathrm{V})$.

$\mathrm{V}_{\mathrm{C}}=$ capacitor charged voltage in Volt $(\mathrm{V})$.

$\mathrm{V}_{\mathrm{d}}=$ capacitor discharged voltage in Volt $(\mathrm{V})$. 


\subsubsection{Wireless Module}

All the data measured by the VOCs sensor node are designed to be sent to the server through a Wi-Fi connection, which is expected to be maintained as long as the system is working and reinitialized every time the system restarts. The WINC1510 Wi-Fi module used is presented in Figure 4.

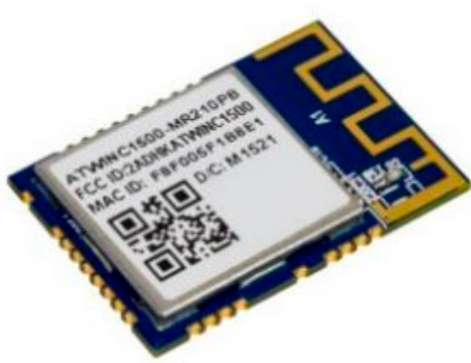

Figure 4. WINC1510 Wi-Fi module.

This module was selected due to its low power consumption, which is associated with the application of $802.11 \mathrm{~b} / \mathrm{g} / \mathrm{n}$ IoT, which is a standard optimized for low-power IoT applications. It is also equipped with a low-noise amplifier (LNA), power amplifier (PA), switch, and power management. Moreover, the module is small in design and uses a micro co-ax (U.FL) connector for an external antenna and SPI to interface with a microcontroller.

\subsubsection{Indoor Air Quality (IAQ) Sensor}

The IAQ sensor module, which has the ability to measure VOCs levels and provide $\mathrm{CO}_{2}$ equivalent and TVOCs equivalent predictions, was used in this system. This sensor uses IAQ-Core, which has $\mathrm{I}_{2} \mathrm{C}$ protocol communication, produces calibrated TVOCs and $\mathrm{CO}_{2}$ equivalent values [31], and was integrated with the main board of the sensor node. The image of the IAQ sensor is presented in Figure 5.

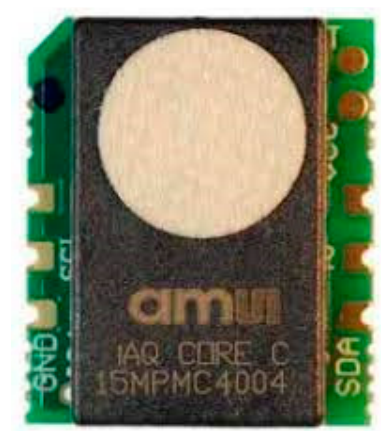

Figure 5. IAQ sensor.

\subsubsection{Software}

The final target of the system is to be able to monitor the indoor TVOCs value in real time, and data visualization is necessary to make it easier for users to read the data. Therefore, the Adafruit Dashboard was used to display the data sent by the VOCs sensor node. This dashboard is a platform developed by adafruit.io and observed to be capable of receiving and visualizing data according to the user's design. The system algorithm applied to monitor the indoor TVOCs value is described as follows (Algorithm 1): 


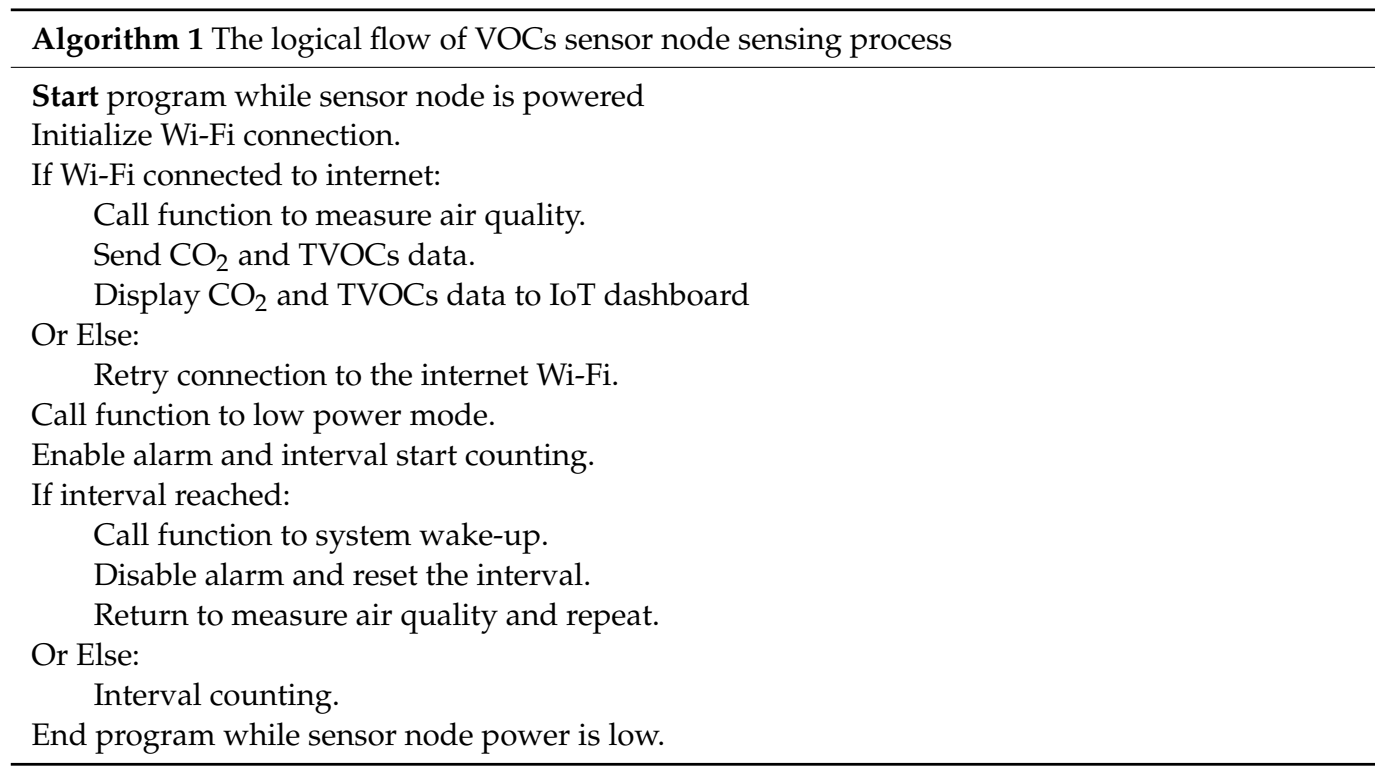

\section{Results and Discussion}

The prototype was verified by testing the component functions, validating the measurement results, calibrating, analyzing the current, voltage, and power consumption, as well as the processing time, and testing the data visualization process. A comprehensive analysis was required to ensure the system developed operates according to the specifications in the design.

\subsection{Device Implementation}

Figure 6 shows the VOCs sensor node prototype assembled and ready to be used. The compact and minimalist design allows for the sensor nodes to be implemented in small spaces.

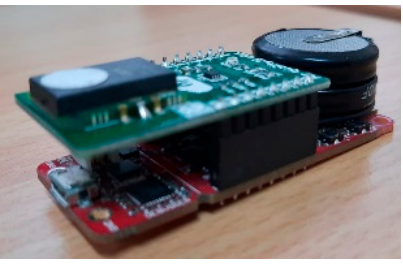

(a)

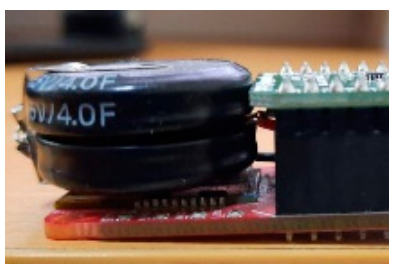

(b)

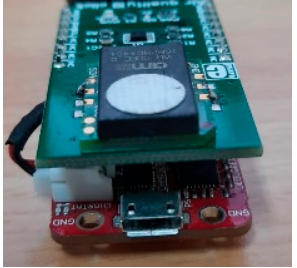

(c)

Figure 6. VOCs sensor node prototype: (a) side view, (b) energy source (supercapacitor), and (c) front view.

\subsection{Functionality Test}

Each component used in the VOCs sensor node was tested for functionality to ensure that they can work properly. The tests were conducted on four main blocks including the energy storage, sensor, processor, and wireless, while the power source was evaluated by measuring the charging and discharging process. The functionality of the supercapacitor is based on its ability to keep the power within a voltage rating according to specifications. Moreover, the mainboard was tested simultaneously with the sensor and Wi-Fi, and its functionality was based on its ability to read the sensor. Figure 7 shows the logic analyzer analysis showing that the mainboard can read the data sent by the VOCs sensor through the $\mathrm{I}_{2} \mathrm{C}$ interface. 


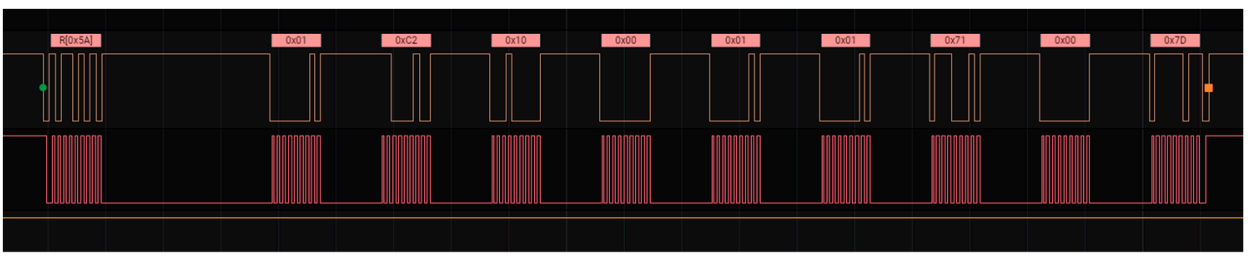

(a)

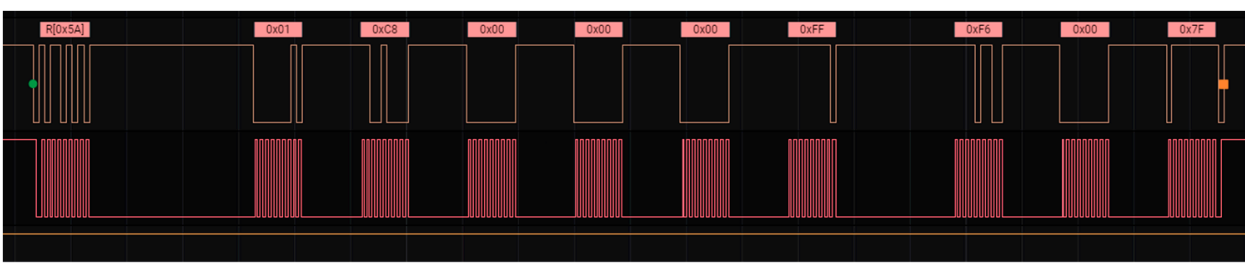

(b)

Figure 7. (a) Response 0x10 means the sensor is warming up, and (b) response 0x00 means the sensor is working well.

The Wi-Fi block was assessed by scanning available wireless and connection ability. The results of the functionality test are presented in the following Table 3.

Table 3. Functionality test results.

\begin{tabular}{ccc}
\hline Block & Testing Parameter & Result \\
\hline Power source & Charging and discharging process & Good \\
Supercapacitor & Reading the sensor and wireless connection & Good \\
Processor & Scanning and connection ability & Good \\
Wireless & Good \\
\hline
\end{tabular}

The VOCs sensor node was validated by comparing the value of its readings with a validator. An industrial portable air quality monitor (BR-Smart BLATN) was used as the validator, as shown in Figure 8a, while the test objects or materials in Figure 8b were used in the test to produce high TVOCs pollutants such as detergent, floor cleaner, and perfume. It is important to note that the VOCs sensor node, industrial portable air quality monitor, and the materials were also placed in a controllable test equipment chamber during the test, as shown in Figure 8c.

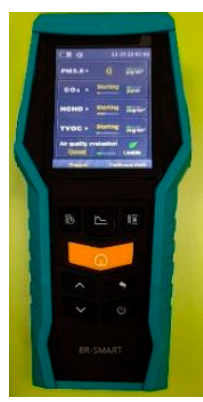

(a)

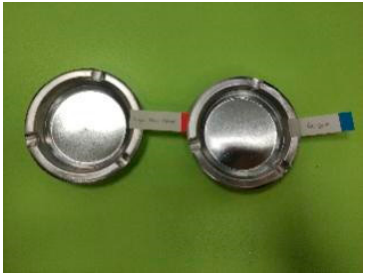

(b)

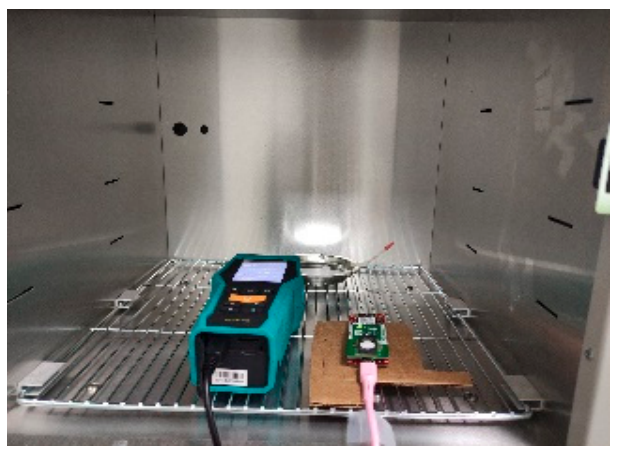

(c)

Figure 8. VOCs validation: (a) VOCs measurement instrument, (b) test object, and (c) test configuration.

The results of the validation process presented in Table 4 showed that the reading values of the VOCs sensor node are close to those of the validator, with the error ob- 
served to range from $-43 \mathrm{ppb}$ to $-20 \mathrm{ppb}$ for the measurement values of $211 \mathrm{ppb}$ to $354 \mathrm{ppb}$, respectively.

Table 4. Validation results.

\begin{tabular}{cccc}
\hline \multirow{2}{*}{ Test Objects } & \multicolumn{3}{c}{ TVOCs Value (ppb) } \\
\cline { 2 - 4 } & VOCs Sensor Node & Validator & Error \\
\hline Indoor air condition & 211 & 254 & -43 \\
Detergent & 278 & 325 & -47 \\
Floor Cleaner & 305 & 342 & -37 \\
Perfume & 354 & 374 & -20 \\
\hline
\end{tabular}

\subsection{Power Requirement Test}

The power was measured to determine the consumption rate of the VOCs sensor node. It is important to note that pre-measurements, such as calibration and validation, are necessary to ensure the accuracy of the tests. Moreover, the power requirement was tested using a power sensor module.

\subsubsection{Power Sensor Test}

The 1NA219 sensor was used to measure the current and voltage of the VOCs sensor node as well as the power value. This involved measuring the voltage across $0.1 \Omega, 1 \%$ sense resistor, and $0.1 \mathrm{~mA}$ resolution with maximal current at $\pm 400 \mathrm{~mA}$ when the internal gain was set at div8. Moreover, $\mathrm{I}_{2} \mathrm{C}$ was used as the interface to communicate with the processor while Arduino Uno was applied to read the INA219 sensor data output, as shown in Figure 9, to avoid interfering with the measurement of the power on the load.

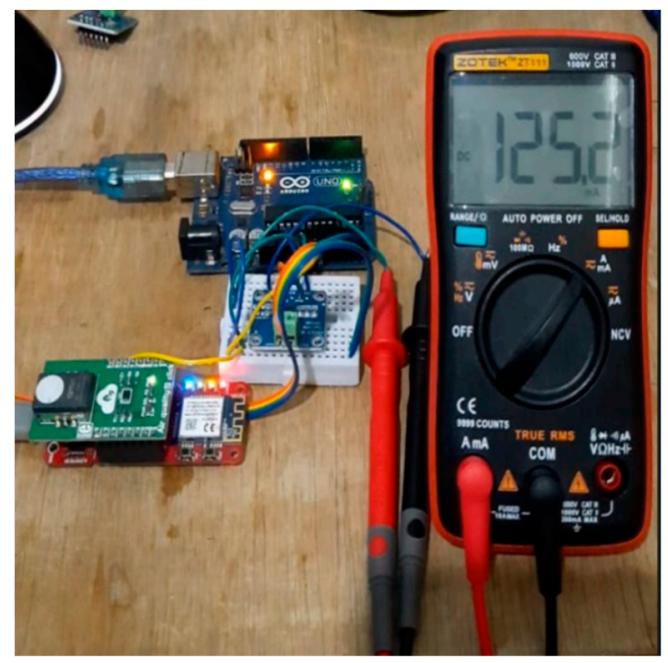

Figure 9. Power measurement.

The results of the 1NA219 sensor were validated as a pre-measurement stage in the process of determining the power in the system. The validation was conducted by comparing the values of the current and voltage measured using the 1NA219 sensor with those obtained from the multimeter. It was discovered that the 1NA219 sensor has a high accuracy lower than $1 \%$ for current as shown in Table 5, while the voltage measurement accuracy was $0.33 \%$ as indicated in Table 6 . 
Table 5. Current measurements.

\begin{tabular}{cccc}
\hline \multirow{2}{*}{ Load Test } & \multicolumn{3}{c}{ Current Value (mA) } \\
\cline { 2 - 4 } & 1NA219 & Multimeter & Accuracy (\%) \\
\hline VOCs node sensor & 119.90 & 120.02 & 0.10 \\
VOCs node sensor with activated 4 LED & 125.90 & 125.20 & 0.56 \\
VOCs node sensor with transmitting data to the cloud & 121.50 & 120.50 & 0.83 \\
\hline
\end{tabular}

Table 6. Voltage measurements.

\begin{tabular}{cccc}
\hline \multirow{2}{*}{ Load Test } & \multicolumn{3}{c}{ Voltage Value (V) } \\
\cline { 2 - 4 } & 1NA219 & Multimeter & Accuracy (\%) \\
\hline VOCs node sensor (VCC) & 3.27 & 3.3 & 0.33 \\
\hline
\end{tabular}

\subsubsection{Power Measurement}

The power on the VOCs sensor nodes was measured based on the algorithms described in the Software subsection. The system has four processes in one cycle interval, which include the initial process, reading of TVOCs values, the transmission of data, and low power mode. The initial process is the first step the system takes when it is turned on and all the components including the Mainboard, sensors, and Wi-Fi are initiated. This stage is usually conducted once as long as the system is running and reinitiated when the system restarts. Moreover, the TVOCs value reading stage involves the measurement of the TVOCs pollutants through the IAQM sensor to produce calibrated TVOCs and $\mathrm{CO}_{2}$ equivalent values [31] that are sent through the server during the data transmitting stage. The successful completion of the data transmission is normally followed by the activation of the low power mode for $30 \mathrm{~min}$ by the system, after which the mode is disabled and the TVOCs value reading stage is repeated for the subsequent data. Figure 10 shows that the highest power consumed was approximately $441.83 \mathrm{~mW}$ from the TVOCs value reading stage. The value reduced drastically to $114.16 \mathrm{~mW}$ when the low power mode was enabled, and this means the mode is important in autonomous indoor TVOCs monitoring. It is also important to note that the data transmission interval is the key to the lifetime of a system working with a specific energy storage capacity. The system was designed to work on low power mode when no data are being transmitted to reduce the power consumption rate.

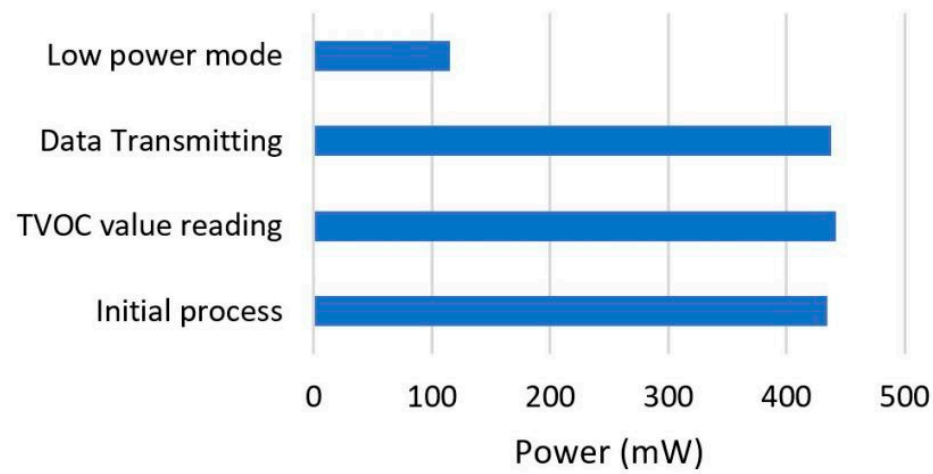

Figure 10. Power measurement data.

\subsubsection{Processing Time Consumption}

The processing time was evaluated in each process as observed with the power measurement. The time interval was set at $30 \mathrm{~min}$ considering the changes in the relatively fixed values and the fact that there was no need for quick monitoring. Figure 11 shows that the time required for the initial process was approximately $2005 \mathrm{~ms}$ with most observed to be for the wireless initialization. The TVOCs value reading process required $2 \mathrm{~ms}$, while the transmission of the two outputs data including $\mathrm{CO}_{2}$ and TVOCs values to the server 
required approximately $3514.6 \mathrm{~ms}$. It is important to note that these are the average values from the five processing rounds conducted.

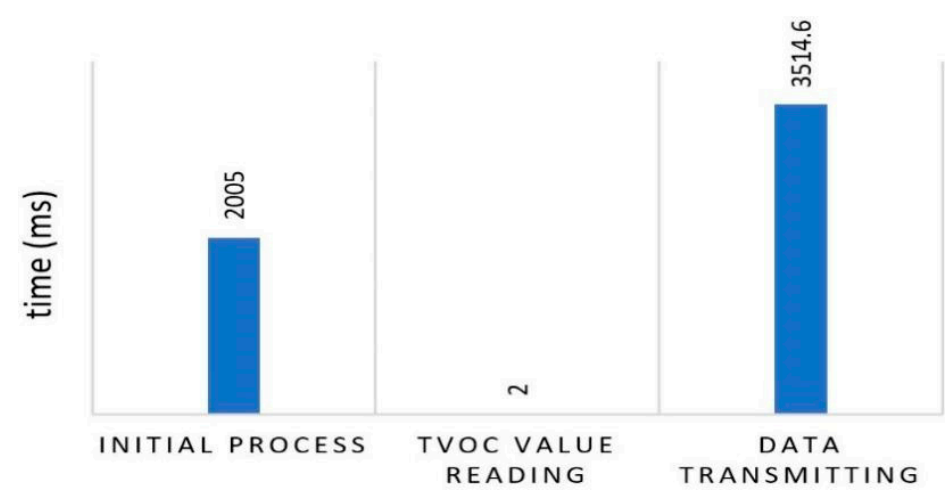

Figure 11. Time measurement.

\subsubsection{Power Source Capacity}

The VOCs sensor node reads and transmits the data at the appropriate time interval. Table 7 shows that the highest power was consumed during the data transmitting process with $0.13 \mathrm{mAh}$, which is $58 \%$ of the overall power consumed in one cycle of sensor node operation as indicated in Figure 12. However, the $2.7 \mathrm{mAh}$ capacity of the supercapacitor was reached in just $139 \mathrm{~ms}$, and this was observed to be a good step in conducting further studies on the application of supercapacitors as an alternative power source.

Table 7. Power source capacity.

\begin{tabular}{cccc}
\hline Process & Power (mA) & Time (ms) & $\begin{array}{c}\text { Power Source } \\
\text { Capacity (mAh) }\end{array}$ \\
\hline Initial process & 132.90 & 2005.00 & 0.07 \\
TVOCs value reading & 135.20 & 2.00 & 0.01 \\
Data transmitting & 134.00 & 3514.60 & 0.13 \\
Low power mode & 35.30 & 1800.00 & 0.02 \\
& Total power consumption & & 0.22 \\
\hline
\end{tabular}

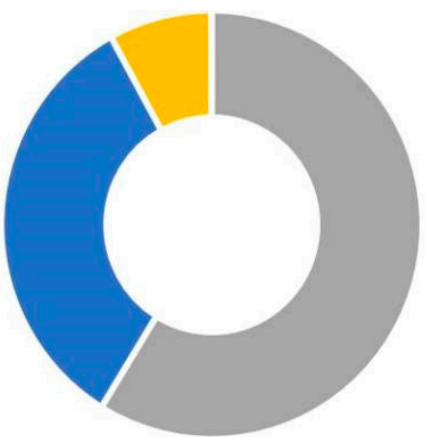

Initial process (3.33\%)

Data Transmitting (58\%)
TVOC value reading $(0.03 \%)$

Low power mode $(7.92 \%)$

Figure 12. Power source capacity percentage.

\subsection{User Interface}

Figure 13 shows the dashboard design to visualize indoor TVOCs value with Message Queuing Telemetry Transport (MQTT) used as the communication protocol between the 
VOCs sensor node and the dashboard to allow the system to be designed to work in real time.

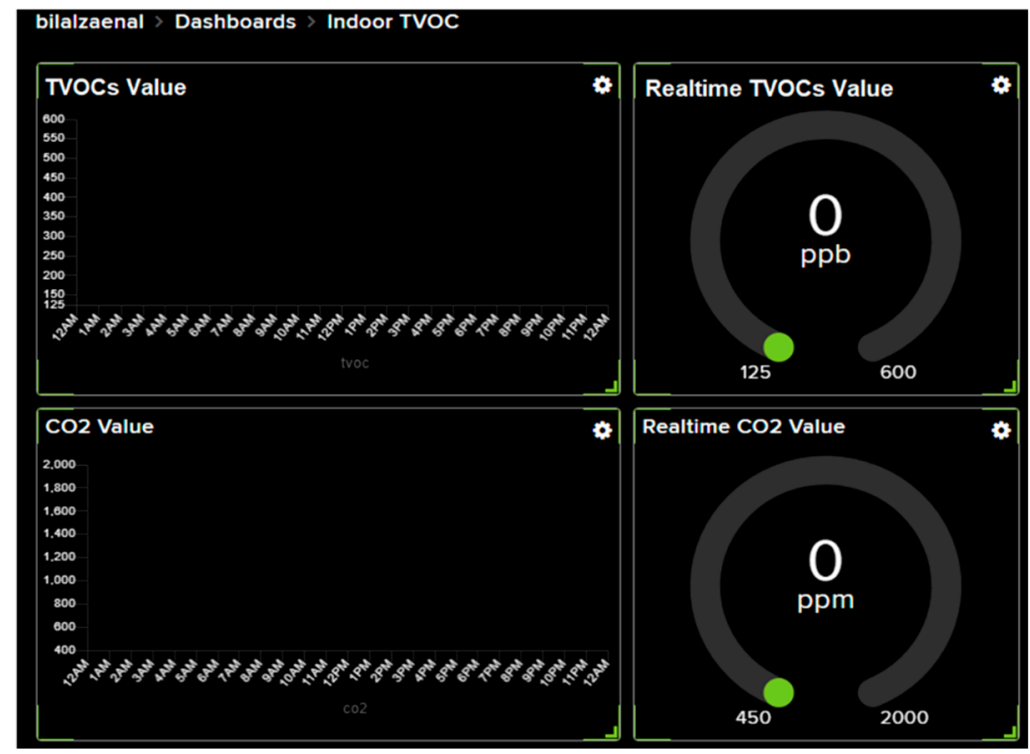

Figure 13. Dashboard design.

\subsection{VOCs Field Experiment}

\subsubsection{Configuration}

The system configuration consists of a sensor node, a server, and a monitoring terminal as shown in Figure 14.

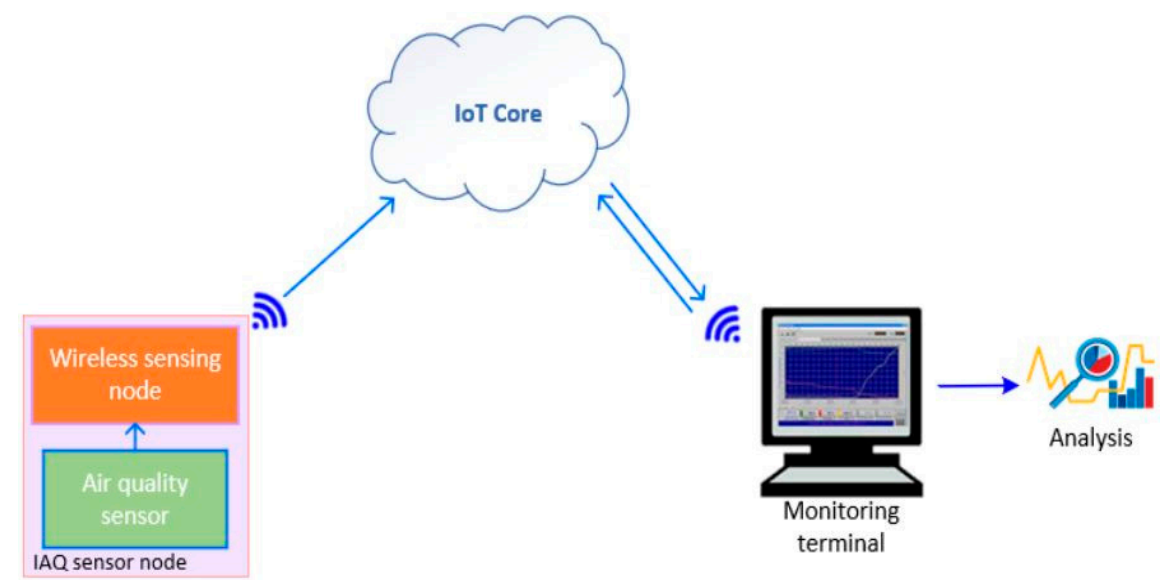

Figure 14. System configuration.

The sensor node was used to read the TVOCs and $\mathrm{CO}_{2}$ values, which were further transmitted to the Adafruit server through an internet connection. It is possible to access the monitoring dashboard from anywhere and at any time through a computer or smartphone on the client side. The TVOCs and $\mathrm{CO}_{2}$ parameter values displayed on the dashboard were $\mathrm{t}$ used in determining the air quality level.

\subsubsection{Result}

Figure 15 shows the TVOCs and $\mathrm{CO}_{2}$ readings on the dashboard in the university laboratory with the TVOCs real-time value recorded to be $175 \mathrm{ppb}$, which means it is at a concentration level 2 as shown in Table 1, thereby indicating that the air quality is good. 


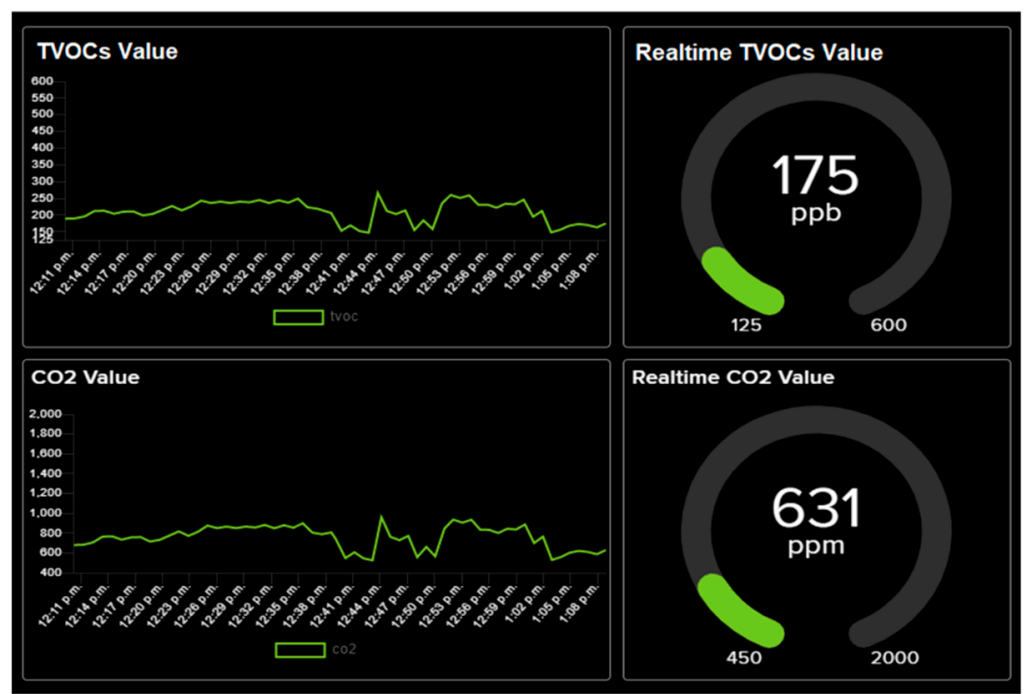

Figure 15. TVOCs and $\mathrm{CO}_{2}$ measurement results on the monitoring terminal dashboard.

The sensor was tested at two different locations as described in Table 8 and observed to be working effectively. Figure 16 shows the IAQ sensor value for $400 \mathrm{~min}$ and the laboratory was discovered to have an average TVOCs value below the quality standard of level $2(<222 \mathrm{ppb})$, while the dormitory was above the quality standard as defined in Table 1.

Table 8. The main characteristics of the measurement area.

\begin{tabular}{|c|c|c|}
\hline Measurement Area & Location & Room Description \\
\hline University & Laboratories of University & $\begin{array}{l}\text { - } \quad \text { Using air conditioner. } \\
\text { - } \quad \text { Sar from outside area. } \\
\text { measurement devices, plastic chairs, wood tables, and } \\
\text { aluminum cupboards. }\end{array}$ \\
\hline University & Dormitory of University & $\begin{array}{l}\text { - } \quad \text { Located nearby the road. } \\
\text { - } \quad \text { Nearby residential and building. } \\
\text { - } \quad \text { Rarely gets fresh air. } \\
\text { - Some stuff inside the room: spring bed mattress, pillow, } \\
\text { wooden table, wooden chair, wooden cupboard, carpet, and } \\
\text { some chemical liquids including perfume, skincare, floor } \\
\text { cleaner, and detergent. }\end{array}$ \\
\hline
\end{tabular}

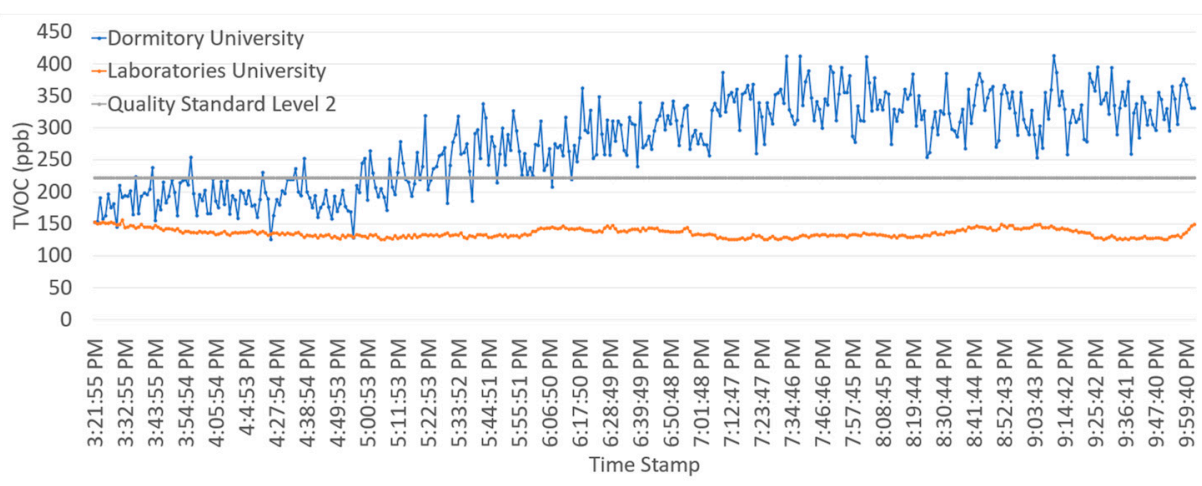

Figure 16. TVOCs measurement results. 


\section{Conclusions}

An autonomous wireless VOCs sensor node prototype with a compact size design and low power algorithm was developed in this study. The total power consumption of the node was recorded to be $0.22 \mathrm{mAh}$ for one cycle of sensor node operation, which includes the initial process, TVOCs value reading, data transmission, and low power mode with a time interval of $30 \mathrm{~min}$. The highest power, $0.13 \mathrm{mAh}$, which is $58 \%$ of the total power consumed in the system, was observed to be consumed during the data transmission process. Moreover, the supercapacitor with 10F capacitance used was able to drive the VOCs sensor node for $139 \mathrm{~s}$, and it is possible to extend its lifetime by either increasing the capacity or harvesting micro energy from the indoor environment. The experiment results also showed that TVOCs and $\mathrm{CO}_{2}$ values were successfully measured and displayed on the monitoring terminal dashboard through the internet connection.

Author Contributions: Conceptualization. C.B.D.K.; methodology. C.B.D.K. and M.B.Z.A.; formal analysis. M.B.Z.A. and A.A.; investigation. M.B.Z.A. and A.A.; supervision. C.B.D.K.; resources. C.B.D.K; writing-original draft preparation. M.B.Z.A. and A.A.; writing-review and editing. C.B.D.K. All authors have read and agreed to the published version of the manuscript.

Funding: This research funding by the Ministry of Science and Technology of Taiwan (MOST: 1102222-E-167-003-MY3).

Institutional Review Board Statement: Not applicable.

Informed Consent Statement: Not applicable.

Data Availability Statement: The data presented in this study are available at the request of the corresponding author.

Acknowledgments: The authors would like to thank the Ministry of Science and Technology of Taiwan for funding support and the Refrigeration, Air Conditioning, and Energy Engineering Department of the National Chin-Yi University of Technology, Taiwan, for support in the system design.

Conflicts of Interest: The authors declare no conflict of interest.

\section{References}

1. The 17 Goals IDepartment of Economic and Social Affairs. Available online: https://sdgs.un.org/goals (accessed on 20 January 2021).

2. Daniel Lawrence, I.; Thiruneelakandan, G.; Jayabal, S.; Thirumal, P. Analysis of Indoor Air Quality and PMV-PPD Model in Dynamic Conditioned Car Cabin. Int. J. Innov. Res. Sci. Eng. Technol. 2014, 3, 15581-15591. [CrossRef]

3. Saini, J.; Dutta, M.; Marques, G. A comprehensive review on indoor air quality monitoring systems for enhanced public health. Sustain. Env. Res. 2020, 30, 6. [CrossRef]

4. Marques, G.; Pires, I.M.; Miranda, N.; Pitarma, R. Air Quality Monitoring Using Assistive Robots for Ambient Assisted Living and Enhanced Living Environments through Internet of Things. Electronics 2019, 8, 1375. [CrossRef]

5. Zhang, Y.; Zhao, Y. Design \& implementation of an Air Quality Monitoring System for Indoor Environment based on Microcontroller. Int. J. Smart Home 2015, 9, 301-312. [CrossRef]

6. Klepeis, N.E.; Nelson, W.C.; Ott, W.R.; Robinson, J.P.; Tsang, A.M.; Switzer, P.; Behar, J.V.; Hern, S.C.; Engelmann, W.H. The National Human Activity Pattern Survey (NHAPS): A resource for assessing exposure to environmental pollutants. J. Expo. Sci. Env. Epidemiol. 2001, 11, 231-252. [CrossRef]

7. Jo, J.; Jo, B.; Kim, J.; Kim, S.; Han, W. Development of an IoT-Based Indoor Air Quality Monitoring Platform. J. Sens. 2020, 2020, 1-14. [CrossRef]

8. Meyer, C. Overview of TVOC and Indoor Air Quality. Renesas Electronics. 2021. Available online: https://www.renesas.com/us/ en/document/whp/overview-tvoc-and-indoor-air-quality (accessed on 17 February 2022).

9. Molhave, L.; Clausen, G.; Berglund, B.; De Ceaurriz, J.; Kettrup, A.; Lindvall, T.; Maroni, M.; Pickering, A.C.; Risse, U.; Rothweiler, H.; et al. Total Volatile Organic Compounds (TVOC) in Indoor Air Quality Investigations. Indoor Air 1997, 7, 225-240. [CrossRef]

10. Adgate, J.L.; Church, T.R.; Ryan, A.D.; Ramachandran, G.; Fredrickson, A.L.; Stock, T.H.; Morandi, M.T.; Sexton, K. Outdoor, Indoor, and Personal Exposure to VOCs in Children. Environ. Health Perspect. 2004, 112, 1386-1392. [CrossRef] [PubMed]

11. World Health Organization (Ed.) Air Quality Guidelines for Europe, 2nd ed.; Regional Office for Europe, World Health Organization: Copenhagen, Denmark, 2000. 
12. US EPA. Indoor Air Quality [IAQ]. 3 July 2014. Available online: https://www.epa.gov/indoor-air-quality-iaq (accessed on 23 January 2022).

13. Umweltbundesamt. Beurteilung von Innenraumluftkontaminationen mittels Referenz- und Richtwerten: Handreichung der Ad-hoc-Arbeitsgruppe der Innenraumlufthygiene-Kommission des Umweltbundesamtes und der Obersten Landesgesundheitsbehörden. Bundesgesundheitsbl-Gesundh.-Gesundh. 2007, 50, 990-1005. [CrossRef] [PubMed]

14. Saad, S.; Andrew, A.; Shakaff, A.; Saad, A.; Kamarudin, A.; Zakaria, A. Classifying Sources Influencing Indoor Air Quality (IAQ) Using Artificial Neural Network (ANN). Sensors 2015, 15, 11665-11684. [CrossRef] [PubMed]

15. Zampolli, S.; Elmi, I.; Ahmed, F.; Passini, M.; Cardinali, G.; Nicoletti, S.; Dori, L. An electronic nose based on solid state sensor arrays for low-cost indoor air quality monitoring applications. Sens. Actuators B Chem. 2004, 101, 39-46. [CrossRef]

16. Hemant, K.; Cyril, R.A.J. Indoor Air Quality Monitoring with Arduino-Based Embedded System for Terrariums. J. Crit. Rev. 2020, 7, 1391-1399. [CrossRef]

17. Zhao, Y.-L.; Tang, J.; Huang, H.-P.; Wang, Z.; Chen, T.-L.; Chiang, C.-W.; Chiang, P.-C. Development of IoT Technologies for Air Pollution Prevention and Improvement. Aerosol Air Qual. Res. 2020, 20, 2874-2888. [CrossRef]

18. De Gennaro, G.; Farella, G.; Marzocca, A.; Mazzone, A.; Tutino, M. Indoor and Outdoor Monitoring of Volatile Organic Compounds in School Buildings: Indicators Based on Health Risk Assessment to Single out Critical Issues. Int. J. Environ. Res. Public Health 2013, 10, 6273-6291. [CrossRef] [PubMed]

19. Tiele, A.; Esfahani, S.; Covington, J. Design and Development of a Low-Cost, Portable Monitoring Device for Indoor Environment Quality. J. Sens. 2018, 2018, 1-14. [CrossRef]

20. Shuheng, S.; Jie, S. Design an Indoor Air Quality Controller Based on LPC2478. Sens. Transducers 2014, 174, 7.

21. Arroyo, P.; Lozano, J.; Suárez, J.I. Evolution of Wireless Sensor Network for Air Quality Measurements. Electronics 2018, 7, 342. [CrossRef]

22. Saini, J.; Dutta, M.; Marques, G. Indoor Air Quality Monitoring Systems Based on Internet of Things: A Systematic Review. Int. J. Environ. Res. Public Health 2020, 17, 4942. [CrossRef] [PubMed]

23. Honeycutt, W.T.; Ley, M.T.; Materer, N.F. Precision and Limits of Detection for Selected Commercially Available, Low-Cost Carbon Dioxide and Methane Gas Sensors. Sensors 2019, 19, 3157. [CrossRef] [PubMed]

24. Pandey, P.; Yadav, R. A Review on Volatile Organic Compounds (VOCs) as Environmental Pollutants: Fate and Distribution. Int. J. Plant Environ. 2018, 4, 14-26. [CrossRef]

25. US EPA. Volatile Organic Compounds' Impact on Indoor Air Quality. 18 August 2014. Available online: https://www.epa.gov/ indoor-air-quality-iaq/volatile-organic-compounds-impact-indoor-air-quality (accessed on 14 December 2021).

26. Total Volatile Organic Compounds (TVOC) and Indoor Air Quality (IAQ). 11 November 2019. Available online: https://www. catsensors.com/media/pdf/Sensor_Sensirion_IAM.pdf (accessed on 12 February 2022).

27. Khanchuea, K.; Rawat, S. An IoT-enabled Platform for Power Consumption Measurement of Low-Power Wireless Sensor Devices In Proceedings of the 2018 2nd International Conference on Engineering Innovation (ICEI), Bangkok, Thailand, 5-6 July 2018; Available online: http:/ / ieeexplore.ieee.org/servlet/opac?punumber=8430214 (accessed on 14 December 2021).

28. Mishra, R.; Saxena, R. Comprehensive review of control schemes for battery and supercapacitor energy storage system. In Proceedings of the 2017 7th International Conference on Power Systems (ICPS), Pune, India, 21-23 December 2017; pp. 702-707. [CrossRef]

29. Hou, S.-Y.; Huang, T.-C.; Chang, Y.-C.; Huang, K.-C. A self powered feed forward boost converter charging scheme for low cost super capacitor applications. In Proceedings of the 2011 International Conference on System Science and Engineering, Macau, China, 8-10 June 2011; pp. 578-581. [CrossRef]

30. Colomer-Farrarons, J.; Miribel-Catala, P.; Saiz-Vela, A.; Samitier, J. A $60 \mu \mathrm{W}$ low-power low-voltage power management unit for a self-powered system based on low-cost piezoelectric powering generators. In Proceedings of the 2019 Proceedings of ESSCIRC, Athens, Greece, 14-18 September 2009; pp. 280-283. [CrossRef]

31. iAQ-Core Indoor Air Quality Sensor Module. 30 April 2015. Available online: https:/ /www.sciosense.com/products/environmentalsensors /iaq-core-c/ (accessed on 19 February 2021).

32. Simple Energy Storage Capacitor Formulae. 14 December 2021. Available online: https://sparks.gogo.co.nz/capacitor-formulae. html (accessed on 14 December 2021). 